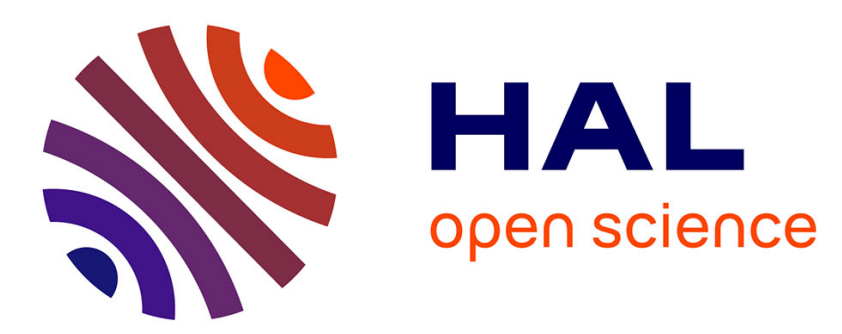

\title{
Endocrine and behavioural responses of sows to human interactions and consequences on reproductive performance
}

\author{
Armelle Prunier, Céline Tallet
}

\section{- To cite this version:}

Armelle Prunier, Céline Tallet. Endocrine and behavioural responses of sows to human interactions and consequences on reproductive performance. The gestating and lactating sow, Wageningen Academic Publishers, 2015, 978-90-8686-253-5. 10.3920/978-90-8686-803-2_12 . hal-01210734

\author{
HAL Id: hal-01210734 \\ https://hal.science/hal-01210734
}

Submitted on 5 Jun 2020

HAL is a multi-disciplinary open access archive for the deposit and dissemination of scientific research documents, whether they are published or not. The documents may come from teaching and research institutions in France or abroad, or from public or private research centers.
L'archive ouverte pluridisciplinaire HAL, est destinée au dépôt et à la diffusion de documents scientifiques de niveau recherche, publiés ou non, émanant des établissements d'enseignement et de recherche français ou étrangers, des laboratoires publics ou privés. 


\title{
12. Endocrine and behavioural responses of sows to human interactions and consequences on reproductive performance
}

\author{
A. Prunier ${ }^{*}$ and C. Tallet \\ INRA, UMR1348 PEGASE, 35590 Saint-Gilles, France; Agrocampus Rennes, UMR1348 \\ PEGASE, 35000 Rennes, France; armelle.prunier@rennes.inra.fr
}

\begin{abstract}
Even though of relatively short duration (approximately $4 \mathrm{~h} /$ sow/reproductive cycle), the time stockpersons spend in contact with reproductive sows and their piglets is of very high importance since it may influence both performance and welfare of the animals. During this time, numerous human-pig interactions occur, especially around birth, breeding and farrowing. These interactions can be qualified as positive, neutral or negative from the animal's perspective. In the present chapter, the literature regarding all types of handlings of sows and their litters is reviewed. Firstly, the immediate and long term effects that painful husbandry practices could have on suckling piglets and on their relationship with humans, as well as the effects that those practises could have on sows when performed nearby, are covered. Then, the consequences of interactions with sows that distinguish between handling during transfer and handling associated with breeding, farrowing supervision and other management tasks are discussed. The consequences of handling type on the reactions of sows and piglets to humans and the possible impacts of this handling on reproductive performance are evaluated. Finally, the question of new practices that could be developed to overbalance the negative interactions inherent to pig management systems, notably by using knowledge of the way animals express their needs or state, are addressed. This review clearly demonstrates the reciprocal effects of humananimal interactions on pigs and humans with consequences not only on performance but also on pig welfare and human satisfaction at work.
\end{abstract}

Keywords: welfare, pig, human-animal relationship, stress

\subsection{Introduction}

In 2009, the average number of hours a stockperson spent handling one reproductive sow was approximately $14 \mathrm{~h}$ in conventional farms in France (Roguet et al., 2011). This duration included tasks devoted to pigs after weaning, as well as tasks with no contact with the animals (cleaning and disinfecting the pens, maintaining and repairing equipment between batches, business tasks), but did not include time devoted to onfarm feed production and to management of pig dejections. It can be estimated that, in conventional piggeries, a stockperson spends less than $4 \mathrm{~h}$ per reproductive sow during one cycle including breeding (less than $1 \mathrm{~h}$ for oestrus detection and artificial 
insemination), farrowing supervision and routine practices applied to the piglets in the litter (about one hour), and monitoring of feeding and health, transfer from one pen or building to another (Roguet et al., 2011). However, when a stockperson is working with a sow, the neighbouring sows may also be influenced by the stockperson's behaviour and by the reaction of the sow he/she is working with. This time spent by stockpersons in contact with reproductive sows and their piglets is of very high importance since it may influence both performance and welfare of the animals (Hemsworth, 2003; Kirkden et al., 2013; Rushen et al., 1999).

Human-pig interactions can be characterized as positive, neutral or negative from the animal's perspective (Hemsworth, 2003; Rushen et al., 1999). Such classification depends on the nature of the interaction and the way the animal perceives it. When the interaction contains fear-provoking elements, such as large size, loud noise, shouts or sudden movements of the stockperson or when it induces pain like during some practices inherent to husbandry routines (for example injection or tail docking), it can be considered as negative or aversive for the animals (Hemsworth, 2003; Rushen et al., 1999). Some of the human-pig interactions can be considered as neutral if they don't contain these pain or fear provoking elements. Such examples would be cleaning and monitoring the material or the animals. These tasks offer the opportunity to habituate the pigs to the presence of people and hence to reduce their fearfulness. The human-animal interactions are positive if they consist in pleasant elements like stroking, speaking softly, or when the stockperson is associated with positive elements, such as distribution of food (Boivin et al., 2003; Sommavilla et al., 2011). Finally, some tasks like transferring the sows from one pen or building to another can be positive, neutral or negative depending notably on the way animals are handled by stockpersons. This can be done gently (use of soft voice, friendly slap etc.), neutrally, or roughly (use of shouts, electric prod, etc.). In modern conventional piggeries, occasions for neutral and positive interactions are less and less frequent due to the automation of feeding and other tasks as well as to the extensive use of slatted floors that minimizes the cleaning tasks. Therefore, the animals' direct experiences with stockpersons are biased increasingly towards negative interactions. The consequences can be so much more pronounced that pigs seem to generalize aversive experiences with one handler to all people (Hemsworth et al., 1994, 1996b). Moreover, it was observed that inconsistent handling with a minority of aversive interactions among positive interactions was as effective at inducing fear from humans as consistent aversive interactions (Hemsworth et al., 1987). Even though the aversive handling was extreme (brief electric shocks with an electric prod), these data suggest that occasional negative experiences can have a significant impact on the way that pigs perceive people. In addition, the unpredictability may cause stress anticipation to human presence (Boivin et al., 2003).

The aim of the present chapter is to review research on human-animal interactions focussing on the reproductive sow. The influence of such interactions occurring throughout the life of sows is taken into account and their consequences in terms of behaviour, physiology and performance are evaluated. Lastly, the question of improving the situation with a special emphasis on a better comprehension by stockpersons of the signals that pigs emit to express their needs is addressed. 


\subsection{Handlings of suckling piglets}

Numerous husbandry practices are routinely applied to very young piglets. They comprise surgical castration in males, tail docking, teeth clipping, iron injection, ear notching, tagging or tattooing in both sexes. Moreover, piglets are often handled at birth, especially in farms where farrowing is supervised, with the aim of decreasing neonatal mortality. All these procedures may have an impact on the piglets but also on the sows as they react to handling of their progeny.

\subsubsection{Impact of painful husbandry practises on suckling piglets}

Shortly after birth, piglets may be handled for removal of placental envelopes and mucous from the nose and mouth, for drying with paper towels or 'cotton', for placing them at the mammary gland or under the heat lamp. Such handling generally improves the survival rate of piglets even though the positive effect of drying is questionable (Andersen et al., 2009; Holyoake et al., 1995; Kirkden et al., 2013). Such practices, especially drying, may be aversive for the piglets and hence may influence their subsequent behaviour. To our knowledge, there is no data in pigs to substantiate this hypothesis, but data in foals have shown that prolonged aversive handling just after birth (restriction and maintenance in a recumbent position, exposure to novel tactile stimuli) modified the way foals responded to a stressor when they were adult (Durier et al., 2012).

Tooth resection of the superior and inferior canines and of corner incisors ( 8 teeth in total) is very common in conventional farms (Fredriksen et al., 2009). It is usually performed within a few days after birth, together with other routine practises such as iron injection, tail docking and sometimes castration. It is carried out by clipping teeth with pliers or grinding them with a rotary grindstone. Tail docking is also very common except in some countries where it is restricted by regulation (Fredriksen et al., 2009). Tail docking is carried out with scalpels, scissors/wire cutters or by cautery with a hot iron. The proportion of the tail that is removed by docking is variable: from only the tip of the tail to up to $3 / 4$ of the tail or more. Ear tattooing, ear notching (V-cut performed with a notcher) or ear tagging (plastic tag applied with an applicator) are quite common in farms rearing pigs for reproduction in order to identify them. Iron administration is systematic in conventional farms. It can be performed by oral route or by intramuscular injection. Surgical castration of male pigs is very common although its application varies a lot between countries (Fredriksen et al., 2009) and is highly debated, at least in European countries. It is usually performed during the first days or weeks of postnatal life. Some pig producers carry out castration at birth or the day after, together with tail docking, iron injection and teeth resection. One or two incisions of the scrotum are realized with a sharp scalpel or scissor. Each testicle is freed from surrounding tissue, externalized and removed either by cutting or pulling/tearing the spermatic cord. In order to perform any of those husbandry practises, it is needed to catch the piglet and to force it to stay immobile. Such handling is in itself stressful for the piglets and induces vocalizations as well as defence movements (Marchant-Forde et al., 2009; Torrey et al., 2009; Weary et al., 1998a). 
Behavioural data recorded during and after these various husbandry procedures as well as endocrine data suggest that they are painful, with surgical castration inducing the most severe pain (Hay et al., 2003; Marchant-Forde et al., 2009; Noonan et al., 1994; Prunier et al., 2005; Sutherland et al., 2008; Torrey et al., 2009; White et al., 1995). In European countries, pig producers have started to use a pharmacologic agent to relieve pain at castration using an analgesic injection (meloxicam) before castration and/or a general anaesthesia performed by $\mathrm{CO}_{2}$ or isoflurane, or a local anaesthesia with lidocaine (Anonymous, 2010; Fredriksen et al., 2009). However, even if those methods mitigate pain, they are not fully effective and animals can still feel some discomfort or even pain (Prunier et al., 2006; Von Borell et al., 2009). In addition, other husbandry procedures are usually performed without any treatment for pain relief (Fredriksen et al., 2009). Since these aversive experiences are paired with the presence of human, they can contribute to develop fearfulness of pigs towards humans. This is of special importance for female piglets that are reared for reproduction and are submitted to the same practices as other piglets. To our knowledge, there has been no attempt to measure the long terms effect of those painful handlings of newborn piglets.

\subsubsection{Impact of non-painful interactions on suckling piglets}

In addition to the influence of husbandry practices, the quality of human contacts during routine activities (cleaning, feeding, animals' inspection) may influence the behaviour of the piglets on a short and long term basis. For example, suckling piglets submitted regularly to negative human interactions (speaking with aggressive tone, moving piglets, demonstrating postural threats) expressed, on the day of weaning, more avoidance reactions towards the person that performed the handling, than piglets submitted to neutral interactions (little attention to the sow and piglets, soft tone of voice) (Sommavilla et al., 2011). However, when piglets were observed in the presence of an unknown person, there was no difference in avoidance reaction between the two groups. In the days following weaning, piglets that were subjected to the aversive human interactions were more aggressive and rested less frequently compared with piglets that had received neutral interactions. However, there was no difference in growth rate and feed intake between the two groups.

There have been very few attempts to measure the long terms effect of those negative ways of handling piglets. However, some data showed that fear of humans in an early age may have negative consequences on later reproduction. Indeed, sows that expressed a high fear of humans at 8 wks of age had lower reproduction success than those that were less fearful at the same age (Janczak et al., 2003). In this experiment, the authors reported that most of the animals' interactions with humans were negative (rough handling) from birth. This suggests that early experience may have long term consequences.

Human handling may also be positive, but studies on the influence of positive handling of piglets are rare. To our knowledge, only Hemsworth and his collaborators worked on this topic. This may be due to the difficulty to handle very young animals, and to the possible interference due to the presence of their mother. However, the first days/weeks of postnatal life are known to be a sensitive period that favours the development of social 
links with long term effects (Bateson, 1979). Indeed, providing piglets with stroking and petting during the first three or eight weeks of life induces a positive attraction to humans compared with an absence of such contacts (Hemsworth and Barnett, 1992; Hemsworth et al., 1986b). Between 10 and 18 wks of age, handled piglets approached humans sooner and interacted more with humans than non-handled animals. Moreover, positivelyhandled boars expressed more sexual behaviours compared with non-handled boars and had ejaculations which lasted longer at 6-7 mo of age.

\subsubsection{Impact on the sows of painful husbandry practices applied to piglets}

During painful husbandry procedures applied to piglets by stockpersons, animals usually demonstrate defensive behaviours and vocalizations (Hay et al., 2003; Marchant-Forde et al., 2009; Noonan et al., 1994; Prunier et al., 2005; Sutherland et al., 2008; Torrey et al., 2009; White et al., 1995). These vocalizations can have specific features, as shown after surgical castration (Puppe et al., 2005). They signal to the dam a need from the piglet and hence are supposed to elicit a reaction from her (Weary and Fraser, 1995). Since these negative experiences are paired with the presence of humans, they can contribute to develop aversive reactions of the sows towards humans. On a very short term basis, sows may react to handling of their piglets by aggressive reactions towards the stockperson. On a longer term basis, sows may become more restless, suspicious and aggressive towards humans even though scientific data are missing to substantiate this hypothesis.

\subsection{Handlings of gilts and sows}

Reproductive sows are currently submitted to various types of handling by humans: injections for vaccination or pharmacological treatments, transfer from one pen or building to the other, detection of oestrus, artificial insemination, and extraction of piglets during farrowing. These handlings are aversive as they induce pain, even of a low intensity, and may impose psychological stress, for instance when it is necessary to restrict the animal in a corner of the pen (group-housed animals receiving an injection). A pain component is necessarily associated with some handling practices, like injections for vaccination, whereas other handlings, such as transfers, can be neutral, aversive or even positive depending on how they are performed by the stockperson. Therefore, in this chapter, we will evaluate separately the impact of handling at transfer from one pen/ building to another and the impact of other management practices. We will also evaluate the impact of positive handlings that can be performed with the specific aim of improving the human-animal relationship.

\subsubsection{Transfer of gilts and sows}

Transfer to either farrowing crates or to the insemination room after weaning is a routine management procedure that occurs many times in the sows' life. The perception of the situation by sows depends on the conditions. Indeed, this transfer can be performed in groups or individually, roughly or calmly, for short or long distances. Transfer in groups 
has the advantage of preventing the animals from the stress of being isolated. There are many tools that stockpersons can use during the transfer in order to facilitate the process. Some tools like electric prods are very aversive to the pigs (Gonyou et al., 1986; Hemsworth and Barnett, 1991; Hemsworth et al., 1996a). Fowler (2008) proposed the use of sticks or shields which are much less aversive. Stockpersons may also simply use their body to direct the animals: they can place themselves behind the animals, speak loudly, and push them with the hand. The effectiveness of these various methods is not clear, and their use would depend on the habits of the stockperson. However, pigs were shown to be sensitive to the posture of humans (Hemsworth et al., 1986c; Miura et al., 1996; Nawroth et al., 2014), and thus the human position and posture may impact the ease of transfer. The response of pigs to human voice is not known but pigs are stressed by high-pitched and/or loud sounds (Eguchi et al., 2007; Weeks, 2008), and thus speaking loudly or shouting may negatively impact the transfer. Pigs are also sensitive to human tactile contacts (Hemsworth and Coleman, 2011) and could be affected by being pushed by a shield or hands. These contacts may not facilitate the transfer since it was shown that the speed of transfer was negatively correlated with the number of pushings done by the stockperson (Lensink et al., 2009a). However, a greater incidence of pushing could be the consequence rather than the cause of a difficult transfer. Beside human behaviour, the configuration of the route may impact the ease of transfer (Grandin, 2010).

To our knowledge, physiological and behavioural data measuring the level of stress perceived by the animals during routine transfers in the piggery are not available. However, it is well known that using electric prods (Gonyou et al., 1986; Hemsworth and Barnett, 1991; Hemsworth et al., 1996a) increases the release of cortisol and it is likely that any rough handling (shouts, kicks...) is stressful for the animals.

\subsubsection{Impact of other husbandry tasks}

Sows are repeatedly handled for various husbandry tasks. These human-animal interactions can be aversive to the animals for two reasons: they are either painful by themselves (injections with needles for example) or the handling is accompanied by shouts, snaps, hits, kicks. When these interactions are not painful by themselves, such as oestrus detection or pregnancy diagnosis with ultrasounds, they can be neutral or positive depending again on the behaviour of the stockperson.

When sows are kept outdoors, it is common to insert a nose-ring in order to prevent them from rooting and damaging the pastures. It is an efficient procedure for that purpose but it modifies the behaviour in a way that suggests reduced welfare (Horrell et al., 2001). It is likely that the procedure of nose ringing is painful and that the animal will again associate human handling to pain but scientific data are missing to substantiate this hypothesis.

Sows are often vaccinated by injections and it is probably aversive. Indeed, a subcutaneous injection of saline in the elbow of cyclic gilts or lactating sows was shown to increase circulating cortisol concentrations, indicating a stress reaction (Robert et al., 1989). The procedure of injections may also increase the fear of humans. Indeed, after three weeks of daily intra-muscular injections of saline to growing pigs, pigs were less confident to 
approach a human than pigs that did not receive any injection (Hemsworth et al., 1996a). For example, the withdrawal distance was increased, the orientation of the head towards a human was decreased and the time to interact with a human was increased in injected pigs compared with control pigs.

In conventional farms, most sows are bred by artificial insemination. Two techniques are widely used, namely, deposition of the semen in the cervix or in the uterus, several centimetres beyond the cervix. In both situations, the catheter is fixed in the cervix with a thickened head in a flexible material. It should be done gently in order to avoid injury. However, the presence of blood on the catheter tip at withdrawal or in backflow semen is common (Sbardella et al., 2014). This is especially true in the case of intrauterine insemination, as shown by the presence of blood in more than $20 \%$ of sows inseminated with this technique. To our knowledge, it has not be evaluated whether the trauma associated with the entry of the catheter is painful or not but it can be suspected that it is.

\subsubsection{Impact of positive handlings}

Many breeders make special efforts to socialise their gilts with humans by giving them additional contacts and spending time within the groups of females. They hope this will lead to long term advantages in their relationship with their sows so that they would be easier to handle and less reactive to the presence of humans around farrowing, thereby facilitating observation and care to piglets. Sows are gregarious and they may rapidly become gregarious towards humans. For instance, Dellmeier and Friend (1991) suggested that human mimicry of sow's social greeting (i.e. sow-sow greeting) could reduce aggressive responses. Remaining passive to the approach of a vocalizing sow will give her the possibility to investigate and touch the person, and this would help the sow to form a positive perception of humans.

Positive handling consisting in soft tactile, visual and auditory contacts during the last days of pregnancy can be effective in rapidly increasing the approach reactions of sows towards the handler. Some parts of the body would be more sensitive than others, even if this has not been scientifically tested yet. Such positive handling would be even more efficient when sows are fed. Dellmeier and Friend (1991) took the example of extensively reared sows to claim that sows can be readily tamed by gentle touching and scratching or stroking. Indeed, it was demonstrated that one minute of contact per day was sufficient to increase the percentage of sows approaching the handler from 33 to $83 \%$ seven days later (English et al., 1999). Approach reactions of gilts also increased very rapidly with such contact but the level remained lower (59\%) than for more experienced sows (English et al., 1999). Giving a food reward (a nut) in addition to 1-min of tactile contact during $10 \mathrm{~d}$ at the end of pregnancy was also shown to improve the confidence score in humans (Andersen et al., 2006).

The effects of positive handling on maternal behaviour are not clear. Generally, authors reported no effect on nursing behaviour, posture changes or piglet mortality (Andersen et al., 2006; English et al., 1999). However, English et al. (1999) found that positive handling of sows decreased the interval between births, and this depended on the parity. In a more 
recent study, Andersen et al. (2006) saw no clear influence of positive handling at the end of pregnancy on the duration of farrowing. However, within the group of control sows (sows without additional positive contacts), they observed that females having a higher confidence score at the end of pregnancy tended to have a shorter farrowing duration. Within the group of positively-handled sows, a similar difference was observed but it was less marked as if the positive handling procedure had partly compensated for the low confidence score observed before its application. Therefore, a positive perception of humans (either spontaneous or after extensive positive handling) may facilitate the farrowing process.

\subsubsection{Parity effect on the sow's reactions to handling}

Parity may affect the responses of sows to handling procedures, likely due to a learning process. Yet, there is no general rule on the effect of parity since very few studies were carried out. In some cases, sows react less to humans with advancing parities. For instance, fear of humans seems to decrease with parity, gilts being less receptive (i.e. expressing less attraction toward humans) to friendly contacts than sows in their third parity (English et al., 1999). Primiparous sows also react more quickly than multiparous sows to handling of their piglets by a human (Held et al., 2006) or to the playback of screams of piglets being handled by a human (Hutson et al., 1992). They may learn that there is no negative consequence of this handling situation, thereby becoming less reactive with time. Evidence of such a learning process was also shown in $90 \mathrm{~kg}$-pigs, where training pigs to be transferred decreased their stress responses and increased the speed of the transfer procedure (Lewis et al., 2008).

In other cases, a greater parity number was associated with higher withdrawal responses in a human approach test, higher speed of transfer to the farrowing pen, and lower number of baulks (Lensink et al., 2009a). The higher withdrawal responses clearly indicated greater fearfulness of humans in older sows. The higher speed of transfer was also likely related to greater fearfulness since fearful animals may move more quickly in order to escape the stockperson who is behind them. This hypothesis is supported by the positive correlation reported between the speed of transfer and the withdrawal responses (Lensink et al., 2009a). The negative correlation observed between the number of baulks and the withdrawal reactions also supports that the lower number of baulks observed in higher parity sows was a sign of greater fearfulness. The observation of an increase in the withdrawal response to humans with advancing parities is in agreement with findings from Hemsworth et al. (1999) but opposite to those of Grandinson et al. (2003) and Vangen et al. (2005). The positive or negative influence of parity on fearfulness at a given age, likely depends on the quality of the interactions until that age. It can be hypothesized that if the balance between negative and positive interactions with humans is clearly biased towards negative interactions, the animals become more and more fearful of humans. 


\subsection{Impact of human-animal interactions on reproductive performances}

It is generally accepted that some stockpersons are able to achieve much better reproductive performance of pigs than others despite similar genetic background of the animals, similar housing, and similar general characteristics of the farm management (e.g. feeding, batch farrowing...). This is substantiated by the observation that reproductive performances vary between integrated farms having very similar management characteristics (Hemsworth et al., 1981b; Ravel et al., 1996). Such differences are generally attributed to the quality of the stockmanship that refers both to technical skills and to the quality of the interactions existing between the stockpersons and the animals (Kirkden et al., 2013).

Quality of the human-animal interactions is supposed to influence the level of fear, and hence the stress level of the animals. With regard to reproduction, a high level of fear stimulates the adrenal axis which in turn inhibits the hypothalamo-pituitary-ovarian axis (Hemsworth, 2003). The relationship between the level of fear and the reproductive performance of pigs has been evaluated either at the farm level (Coleman et al., 2000; Hemsworth et al., 1981a, 1989, 1999) or at the animal level (Janczak et al., 2003; Lensink et al., 2009a,b). At the farm level, significant relationships between indicators of fearfulness measured during pregnancy (Hemsworth et al., 1981a) or during lactation (Hemsworth et al., 1999) were observed. In addition, it was demonstrated that the number of very negative interactions (e.g. forceful slaps) observed during regular tasks (e.g. cleaning, oestrus detection, feeding) was positively correlated with behavioural indicators of fearfulness during pregnancy and negatively correlated with reproductive performance. Yet, correlations between fearfulness and less negative interactions (e.g. 'normal' slaps and kicks) were weaker and those with positive interactions (e.g. patting or stroking) were very low (Hemsworth et al., 1996a). Attempts to improve the quality of the human-pig interactions by an educational program of stockpersons failed to increase the reproductive performance of pigs despite a success in terms of percentage of negative interactions performed and of sow fearfulness level (Coleman et al., 2000). Similarly, in a more classical experimental study, positive handling (petting, food reward and gentle talk) during 11-13 d at the end of pregnancy did not change the behaviour of sows in early lactation or their reproductive performance (numbers of stillborn, live born and crushed piglets; Andersen et al., 2006).

When relationships between the level of fearfulness and reproductive variables were analysed at the individual level, significant positive relations were established between the fear level of sows towards humans at 8 wks of age and the later inter-birth intervals when they farrowed. Fear from humans could be associated with more fearful or stressed temperaments. Tendencies for a positive relation between sow fear level and the number of stillborn and neonatal mortality were also reported (Janczak et al., 2003). Similarly, Lensink et al. (2009b) observed that the number of crushed piglets at first farrowing tended to increase with greater fear levels from humans measured in sows either at 6 mo of age or at the end of pregnancy. These same authors also showed, in a second study, a significant correlation between withdrawal reactions from humans measured at the end of pregnancy and crushing level of piglets in early lactation (Lensink et al., 2009a). 
However, the level of fearfulness also increased with parity number of the sows so that the effects of fearfulness vs. parity could not be dissociated. Indeed, the incidence of crushing of piglets is also known to increase with parity due to increased bodyweight and lameness of sows (Prunier et al., 2014; Weary et al., 1998b).

Several experiments were conducted to test the hypothesis that a high level of fear stimulates the adrenal axis which will, in turn, inhibit the hypothalamo-pituitary-ovarian axis. Development of the adrenals (measured as the surface area of the cortex or weight of the glands), and plasma concentrations of cortisol (free or total) in basal situation or in response to a stressor or to an adrenocorticotropic hormone (ACTH) injection were measured in growing pigs submitted repeatedly $(0.5$ to $5 \mathrm{~min} / \mathrm{d}$ during 3 to $5 \mathrm{~d} / \mathrm{wk}$ and 3 to $12 \mathrm{wks} / \mathrm{pig}$ ) to various types of human handling (Gonyou et al., 1986; Hemsworth and Barnett, 1991; Hemsworth et al., 1981a, 1986a, 1987, 1996a). Results indicate clear signs of chronic activation of the adrenal axis when pigs are submitted to an aversive treatment including electric shocks. However, when comparing minimal interactions with positive interactions (due to tactile stimulations such as rubbing or stroking) or negative interactions (due to daily intra-muscular injections), differences related to the adrenal axis were rarely significant (Gonyou et al., 1986; Hemsworth et al., 1986a, 1987, 1996a). In early pregnant gilts, free and total cortisol concentrations were greater in aversively- than in positively-treated gilts (Pedersen et al., 1998). When measured in gilts having minimal contacts with humans, cortisol concentrations were generally closer to those of positively- than aversively-treated gilts. Nevertheless, the negative influence of hormones from the adrenal axis on the various components of the reproductive axis has not been clearly established (Turner et al., 2005; Von Borell et al., 2007). Therefore, the impact of the quality of the human interactions on the reproductive performance of gilts and sows should be researched in situations that are not extreme in terms of repeated aversive interactions imposed by humans.

It can be assumed that a high level of fear of humans by pigs complicates many husbandry tasks and renders them less efficient. For example, if sows have a high level of fear, they will get excited at the approach of humans during farrowing which will increase piglet mortality via longer farrowing or greater crushing incidence. Indeed, comparing outdoor herds with a low $(<16.5 \%)$ or high $(>16.5 \%)$ piglet mortality rate during lactation, Berger et al. (1997) observed that the percentage of farmers watching sows at parturition was greater in the group of herds with the higher mortality. This may be interpreted as a negative influence of the human presence disturbing the farrowing process. It may also be assumed that farmers with a herd having a higher mortality rate make more efforts to reduce it and hence are more present at farrowing in order to assist the sows. If both hypotheses are true, a negative vicious circle will be established.

Finally, it can be postulated that the behaviour of stockpersons towards pigs is positively related to their technical skills (Figure 12.1). Such behaviours of the stockpersons were found to be related to their general beliefs and attitudes about pigs (Hemsworth, 2003). Significant relationships between personality traits (e.g. self-assured, self-disciplined or emotionality) and reproductive performance of sows were also demonstrated (Ravel et al., 1996). In addition to those personal features, it is very likely that the organization 


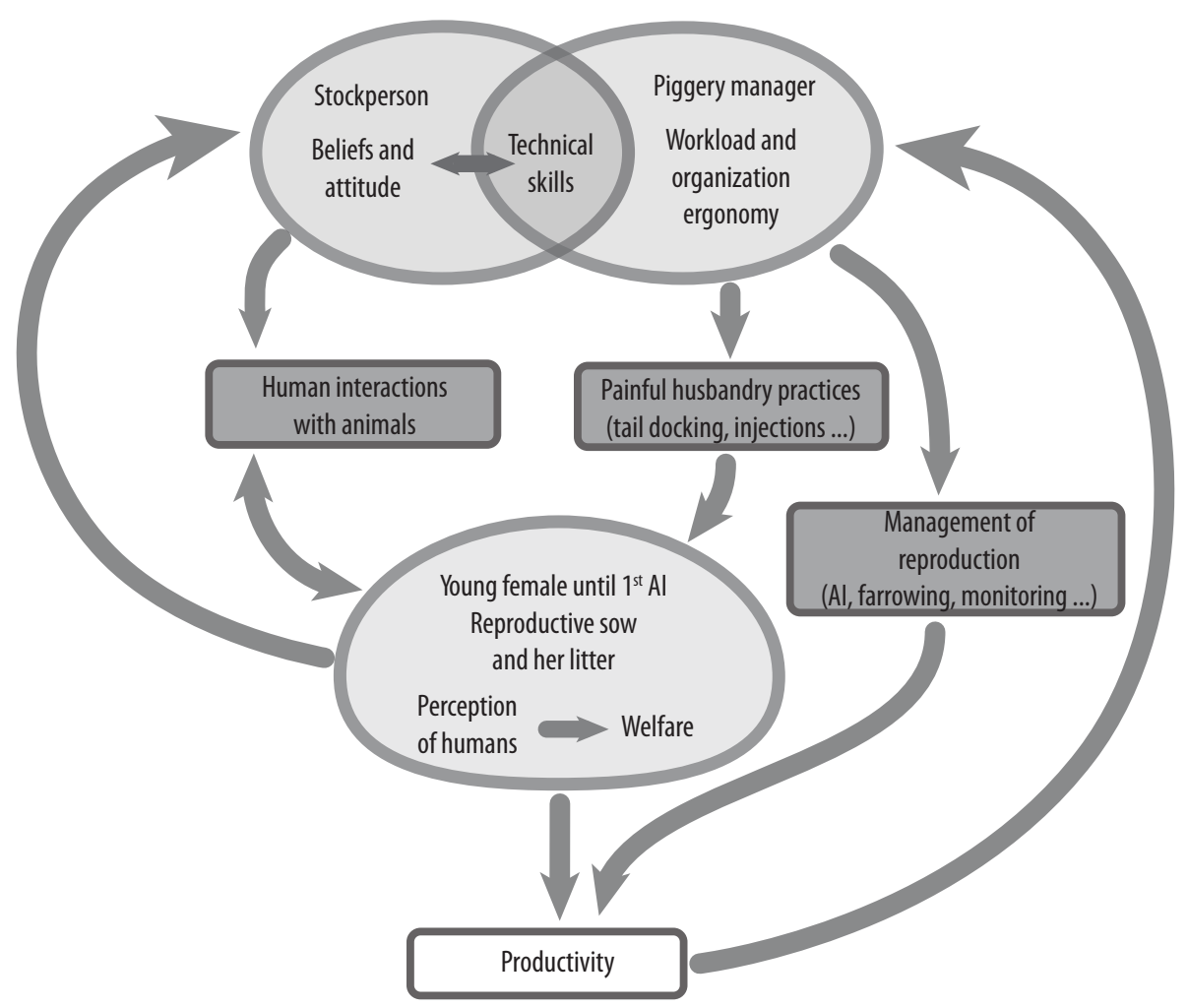

Figure 12.1. Schematic representation of interactions between animals, farm management and stock persons and, possible consequences on animal welfare, stockpersons' job satisfaction and reproductive performance of sows.

of the work and the conception of the housing and equipment either facilitates or complicates the work of the stockpersons with the animals, hence influencing the quality of the human-animal interactions and the efficiency of the tasks performed (Figure 12.1). Therefore, quality of the interactions with the pigs and quality of the work performed by the stockpersons are probably highly interrelated. To our knowledge, there are no scientific data to substantiate this hypothesis.

\subsection{Improving human-animal interactions based on a better understanding of the animals' expressions}

Even if there are many potential negative situations involving handling of pigs, there are different ways to perform these tasks depending on the environmental constraints and also the human attitude (Hemsworth and Coleman, 2011). One way to overbalance the negative interactions inherent to pig management could be to strengthen the understanding of the ways pigs express their needs. Indeed, pigs are quite expressive in their behaviour, which is indicative of their perception of the situation (discomfort, 
agreeability etc.). Humans are receivers of these expressions and could interpret them to react accordingly. There are evidences from empirical studies that there is some contagion of emotion (both suffering and happiness) between pigs and humans, suggesting some understanding of the pigs' state by stockpersons (Fiorelli et al., 2012; Porcher, 2011). Some publications showed that humans are sensitive to signals from pigs and attempt to interpret their meaning. For example, the vocalizations emitted by piglets during a painful practice such as surgical castration can be interpreted by humans as indicating a strong emotional state with a negative valence (Tallet et al., 2010). Interestingly, pig caretakers seemed to interpret these vocalizations less negatively than naïve students and more experienced ethologists. The repeated hearing of these negative sounds may lead to habituation (Talling et al., 1998) but stockpersons may also use a kind of psychological defence to protect them or detach them, such as exhibited by veterinary students towards animal suffering (Paul and Podberscek, 2000).

Body language of animals is also of importance in the evaluation of their emotionality. Welmesfelder and her colleagues developed a method to assess the animal as a whole using videos, the so-called 'qualitative assessment' method, to evaluate emotionality (Wemelsfelder, 2007). Its efficiency to evaluate emotionality of many species, including pigs, has been proven (Wemelsfelder et al., 2000, 2003, 2012). Indeed, results using this method are correlated with quantitative observations of behaviour such that, for instance, animals can be classified as nervous, tense or fearful. In addition, this evaluation is highly repeatable and does not seem to depend on previous experience of humans with the animals (Wemelsfelder et al., 2012).

Consequently, stockpersons can perceive and interpret the signals emitted by pigs, and this can be a basis for them to adapt their contacts with the animals, provided they do not develop an indifferent attitude towards the pigs. Such an understanding of pigs' behaviour should be used to develop practical solutions when a stockperson faces an animal expressing negative states like fear or pain; the aim being to decrease those expressions associated with poor welfare. Such an adaptation should benefit the pigs but also the handler. Indeed, humans are sensitive to pigs being in a positive state (Fiorelli $e t$ al., 2012; Tallet et al., 2010; Wemelsfelder et al., 2012). Developing a better understanding of the pigs' needs by the stockpersons handling them could lead to less negative reactions from the pigs which could, in turn, help to increase the satisfaction of workers since there is a direct link between animals' behaviour and job satisfaction (Hemsworth and Coleman, 2011).

\subsection{Conclusions}

Interactions between sows and humans occur throughout the life of sows and may influence the subsequent way the sows will react to humans, especially their fear reactions. These interactions are not evenly distributed during the sow's life but occur more frequently at special moments: shortly after birth, around breeding (oestrus detection, artificial insemination), and around farrowing. The quality of the sow-human interactions may influence the reproductive performance of the animals via different types of mechanisms 
including the establishment of a chronic stress in sows, which is detrimental for the reproductive axis, difficulties for stockpersons to efficiently perform husbandry tasks, and nervousness of the sows that may induce piglet crushing shortly after farrowing. The quality of these interactions not only influences the welfare and performance of the sows and piglets but also the way stockpersons perceive their work. Once more, various types of mechanisms may be involved, including the contagion of emotions between humans and animals, and the stockperson satisfaction to perform properly a task or to obtain better reproductive performance from the animals. Therefore, improving the quality of the interactions should benefit both the humans and the animals. Various levers could be activated to improve these interactions. As demonstrated by Hemsworth and co-workers, improving the attitudes of stockpersons by learning programs holds much promise (Coleman et al., 2000). Improving the conception of buildings and equipment should also contribute to better human-animal interactions. This is of particular importance when transferring pigs from one pen or building to another (Hemsworth, 2007). The organization of the tasks to be done and decisions regarding the management of the piggery are also of importance since they will influence the workload and hence the ability for stockpersons to work with ease.

\section{References}

Andersen, I.L., Berg, S., Boe, K.E. and Edwards, S., 2006. Positive handling in late pregnancy and the consequences for maternal behaviour and production in sows. Applied Animal Behaviour Science 99: 64-76.

Andersen, I.L., Haukvik, I.A. and Boe, K.E., 2009. Drying and warming immediately after birth may reduce piglet mortality in loose-housed sows. Animal 3: 592-597.

Anonymous, 2010. European declaration on alternatives to surgical castration of pigs on the invitation of the European Commission and the belgium presidency. Available at: www. alternativepig.eu/partnership/declaration.html.

Bateson, P., 1979. How do sensitive periods arise and what are they for ? Animal Behaviour 27: 470-486.

Berger, F., Dagorn, J., Le Denmat, M., Quillien, J.P., Vaudelet, J.C. and Signoret, J.P., 1997. Perinatal losses in outdoor pig breeding. A survey of factors influencing piglet mortality. Annales De Zootechnie 46: 321-329.

Boivin, X., Lensink, B.J., Tallet, C. and Veissier, I., 2003. Stockmanship and farm animal welfare. Animal Welfare 12: 479-492.

Coleman, G.J., Hemsworth, P.H., Hay, M. and Cox, M., 2000. Modifying stockperson attitudes and behaviour towards pigs at a large commercial farm. Applied Animal Behaviour Science 66: 11-20.

Dellmeier, G.R. and Friend, T.H., 1991. Behaviour and extensive management of domestic sows (Sus scrofa) and litters. Applied Animal Behaviour Science 29: 327-341.

Durier, V., Henry, S., Sankey, C., Sizun, J. and Hausberger, M., 2012. Locomotor inhibition in adult horses faced to stressors: a single postpartum experience may be enough! Frontiers in Psychology 3: 442. 
Eguchi, Y., Uetake, K. and Tanaka, T., 2007. Study of technical development using olfactory stimuli and auditory stimuli for behavior control of wild boar. Journal of Azabu University 15/16: 190-193.

English, P.R., Grant, S.A., McPherson, O. and Edwards, S.A., 1999. Evaluation of the effects of the positive 'befriending' of sows and gilts ('pleasant' treatment) prior to parturition and in early lactation on sow behaviour, the process of parturition and piglet survival. In: Russel, A.J.F., Morgan, C.A., Savory, C.J., Appleby, M.C. and Lawrence, T.L.J. (eds.) Farm animal welfare who writes the rules? Proceedings of an international symposium organized by The British Society of Animal Science, Edinburgh, UK, 1999. Occasional Publication - British Society of Animal Science, pp. 132-136.

Fiorelli, C., Mouret, S. and Porcher, J., 2012. Rationalities for working with animals: producing, living together and self-fulfilling. INRA Productions Animales 25: 181-192.

Fowler, M., 2008. Restraint and handling of wild and domestic animals. Third edition. WileyBlackwell, Hoboken, NJ, USA, 470 pp.

Fredriksen, B., Font i Furnols, M., Lundström, K., Migdal, W., Prunier, A., Tuyttens, F.A.M. and Bonneau, M., 2009. Practice on castration of piglets in Europe. Animal 3: 1480-1487.

Gonyou, H.W., Hemsworth, P.H. and Barnett, J.L., 1986. Effects of frequent interactions with humans on growing pigs. Applied Animal Behaviour Science 16: 269-278.

Grandin, T., 2010. How to improve livestock handling and reduce stress. In: Grandin, T. (ed.) Improving animal welfare - a practical approach. Cambridge University Press, Cambridge, UK, pp. 64-87.

Grandinson, K., Rydhmer, L., Strandberg, E. and Thodberg, K., 2003. Genetic analysis of on-farm tests of maternal behaviour in sows. Livestock Production Science 83: 141-151.

Hay, M., Vulin, A., Génin, S., Sales, P. and Prunier, A., 2003. Assessment of pain induced by castration in piglets: behavioral and physiological responses over the subsequent 5 days. Applied Animal Behaviour Science 82: 201-218.

Held, S., Mason, G. and Mendl, M., 2006. Maternal responsiveness of outdoor sows from first to fourth parities. Applied Animal Behaviour Science 98: 216-233.

Hemsworth, P.H., 2003. Human-animal interactions in livestock production. Applied Animal Behaviour Science 81: 185-198.

Hemsworth, P.H., 2007. Behavioural principles of pig handling. In: Grandin, T. (ed.) Livestock handling and transport. CABI, Wallingford, UK, pp. 214-227.

Hemsworth, P.H. and Barnett, J.L., 1991. The effects of aversively handling pigs, either individually or in groups, on their behaviour, growth and corticosteroids. Applied Animal Behaviour Science 30: 61-72.

Hemsworth, P.H. and Barnett, J.L., 1992. The effects of early contact with humans on the subsequent level of fear of humans in pigs. Applied Animal Behaviour Science 35: 83-90.

Hemsworth, P.H., Barnett, J.L. and Campbell, R.G., 1996a. A study of the relative aversiveness of a new daily injection procedure for pigs. Applied Animal Behaviour Science 49: 389-401.

Hemsworth, P.H., Barnett, J.L. and Hansen, C., 1981a. The influence of handling by humans on the behavior, growth and corticosteroids in the juvenile female pig. Hormones and Behavior 15: 396-403.

Hemsworth, P.H., Barnett, J.L. and Hansen, C., 1986a. The influence of handling by humans on the behavior, reproduction and corticosteroids of male and feamle pigs. Applied Animal Behaviour Science 15: 303-314. 
Hemsworth, P.H., Barnett, J.L. and Hansen, C., 1987. The influence of inconsistent handling by humans on the behaviour, growth and corticosteroids of young pigs. Applied Animal Behaviour Science 17: 245-252.

Hemsworth, P.H., Barnett, J.L., Coleman, G.J. and Hansen, C., 1989. A study of the relationships between the attitudinal and behavioural profiles of stockpersons and the level of fear of human and reproductive performance of commercial pigs. Applied Animal Behaviour Science 23: 301-314.

Hemsworth, P.H., Barnett, J.L., Hansen, C. and Gonyou, H.W., 1986b. The influence of early contact with humans on subsequent behavioural response of pigs to humans. Applied Animal Behaviour Science 15: 55-63.

Hemsworth, P.H., Brand, A. and Willems, P., 1981b. The behavioural response of sows to the presence of human beings and its relation to productivity. Livestock Production Science 8: 67-74.

Hemsworth, P.H. and Coleman, G.J., 2011. Changing stockperson attitudes and behaviour. In: Hemsworth, P.H. and Coleman, G.J. (eds.) Human-livestock interactions: the stockperson and the productivity and welfare of intensively farmed animals. CABI, Wallingford, UK, pp. 135-152.

Hemsworth, P.H., Coleman, G.J. and Barnett, J.L., 1994. Improving the attitude and behaviour of stockpersons towards pigs and the consequences on the behaviour and reproductive performance of commercial pigs. Applied Animal Behaviour Science 39: 349-362.

Hemsworth, P.H., Gonyou, H.W. and Dziuk, P.J., 1986c. Human communication with pigs: the behavioural response of pigs to specific human signals. Applied Animal Behaviour Science 15: 45-54.

Hemsworth, P.H., Pedersen, V., Cox, M., Cronin, G.M. and Coleman, G.J., 1999. A note on the relationship between the behavioural response of lactating sows to humans and the survival of their piglets. Applied Animal Behaviour Science 65: 43-52.

Hemsworth, P.H., Price, E.O. and Borgwardt, R., 1996b. Behavioural responses of domestic pigs and cattle to humans and novel stimuli. Applied Animal Behaviour Science 50: 43-56.

Holyoake, P.K., Dial, G.D., Trigg, T. and King, V.L., 1995. Reducing pig mortality through supervision during the perinatal period. Journal of Animal Science 73: 3543-3551.

Horrell, R.I., A’Ness, P.J.A., Edwards, S.A. and Eddison, J.C., 2001. The use of nose-rings in pigs: consequences for rooting, other functional activities, and welfare. Animal Welfare 10: 3-22.

Hutson, G.D., Argent, M.F., Dickenson, L.G. and Luxford, B.G., 1992. Influence of parity and time since parturition on responsiveness of sows to a piglet distress call. Applied Animal Behaviour Science 34: 303-313.

Janczak, A.M., Pedersen, L.J., Rydhmer, L. and Bakken, M., 2003. Relation between early fear- and anxiety-related behaviour and maternal ability in sows. Applied Animal Behaviour Science 82: 121-135.

Kirkden, R.D., Broom, D.M. and Andersen, I.L., 2013. Piglet mortality: management solutions. Journal of Animal Science 91: 3361-3389.

Lensink, B.J., Leruste, H., De Bretagne, T. and Bizeray-Filoche, D., 2009a. Sow behaviour towards humans during standard management procedures and their relationship to piglet survival. Applied Animal Behaviour Science 119: 151-157.

Lensink, B.J., Leruste, H., Le Roux, T. and Bizeray-Filoche, D., 2009b. Relationship between the behaviour of sows at 6 months old and the behaviour and performance at farrowing. Animal 3: 128-134. 
Lewis, C.R.G., Hulbert, L.E. and McGlone, J.J., 2008. Novelty causes elevated heart rate and immune changes in pigs exposed to handling, alleys, and ramps. Livestock Science 116: 338-341.

Marchant-Forde, J.N., Lay, Jr., D.C., McMunn, K.A., Cheng, H.W., Pajor, E.A. and Marchant-Forde, R.M., 2009. Postnatal piglet husbandry practices and well-being: the effects of alternative techniques delivered separately. Journal of Animal Science 87: 1479-1492.

Miura, A., Tanida, H., Tanaka, T. and Yoshimoto, T., 1996. The influence of human posture and movement on the approach and escape behaviour of weanling pigs. Applied Animal Behaviour Science 49: 247-256.

Nawroth, C., Ebersbach, M. and Von Borell, E., 2014. Juvenile domestic pigs (Sus scrofa domestica) use human-given cues in an object choice task. Animal Cognition 17: 701-713.

Noonan, G.J., Rand, J.S., Priest, J., Ainscow, J. and Blackshaw, J.K., 1994. Behavioural observations of piglets undergoing tail docking, teeth clipping and ear notching. Applied Animal Behaviour Science 39: 203-213.

Paul, E.S. and Podberscek, A.L., 2000. Veterinary education and student's attitude towards animal welfare. Veterinary Records 149: 269-272.

Pedersen, V., Barnett, J.L., Hemsworth, P.H., Newman, E.A. and Schirmer, B., 1998. The effects of handling on behavioural and physiological responses to housing in tether-stalls among pregnant pigs. Animal Welfare 7: 137-150.

Porcher, J., 2011. The relationship between workers and animals in the pork industry: a shared suffering. Journal of Agricultural and Environmental Ethics 24: 3-17.

Prunier, A., Bonneau, M., Von Borell, E.H., Cinotti, S., Gunn, M., Frediksen, B., Giersing, M., Morton, D.B., Tuyttens, F.A.M. and Velarde, A., 2006. A review of the welfare consequences of surgical castration in piglets and the evaluation of non-surgical methods. Animal Welfare 15: 277-289.

Prunier, A., Lubac, S., Mejer, H., Roepstorff, A. and Edwards, S.A., 2014. Health, welfare and production problems in organic suckling piglets. Organic Agriculture 4: 107-121.

Prunier, A., Mounier, A.M. and Hay, M., 2005. Effects of castration, tooth resection, or tail docking on plasma metabolites and stress hormones in young pigs. Journal of Animal Science 83: 216-222.

Puppe, B., Schon, P.C., Tuchscherer, A. and Manteuffel, G., 2005. Castration-induced vocalisation in domestic piglets, Sus scrofa: complex and specific alterations of the vocal quality. Applied Animal Behaviour Science 95: 67-78.

Ravel, A., D'Allaire, S. and Bigras-Poulin, M., 1996. Influence of management, housing and personality of the stockperson on preweaning performances on independent and integrated swine farms in Quebec. Preventive Veterinary Medicine 29: 37-57.

Robert, S., De Passillé, A.M.B., St-Pierre, N., Dubreuil, P., Pelletier, G., Petitclerc, D. and Brazeau, P., 1989. Effect of the stress of injections on the serum concentration of cortisol, prolactin, and growth-hormone in gilts and lactating sows. Canadian Journal of Animal Science 69: 663-672.

Roguet, C., Renaud, H. and Duflot, B., 2011. Productivité du travail en elevage porcin: comparaison européenne et facteurs de variation. Journees de la Recherche Porcine en France 43: 251-252.

Rushen, J., Taylor, A.A. and De Passillé, A.M., 1999. Domestic animals' fear of humans and its effect on their welfare. Applied Animal Behaviour Science 65: 285-303.

Sbardella, P.E., Ulguim, R.R., Fontana, D.L., Ferrari, C.V., Bernardi, M.L., Wentz, I. and Bortolozzo, F.P., 2014. The post-cervical insemination does not impair the reproductive performance of primiparous sows. Reproduction in Domestic Animals 49: 59-64. 
Sommavilla, R., Hoetzel, M.J. and Dalla Costa, O.A., 2011. Piglets' weaning behavioural response is influenced by quality of human-animal interactions during suckling. Animal 5: 1426-1431.

Sutherland, M.A., Bryer, P.J., Krebs, N. and McGlone, J.J., 2008. Tail docking in pigs: acute physiological and behavioural responses. Animal 2: 292-297.

Tallet, C., Spinka, M., Maruscakova, I. and Simecek, P., 2010. Human perception of vocalizations of domestic piglets and modulation by experience with domestic pigs (Sus scrofa). Journal of Comparative Psychology 124: 81-91.

Talling, J.C., Waran, N.K., Wathes, C.M. and Lines, J.A., 1998. Sound avoidance by domestic pigs depends upon characteristics of the signal. Applied Animal Behaviour Science 58: 255-266.

Torrey, S., Devillers, N., Lessard, M., Farmer, C. and Widowski, T., 2009. Effect of age on the behavioral and physiological responses of piglets to tail docking and ear notching. Journal of Animal Science 87: 1778-1786.

Turner, A.I., Hemsworth, P.H. and Tilbrook, A.J., 2005. Susceptibility of reproduction in female pigs to impairment by stress or elevation of cortisol. Domestic Animal Endocrinology 29: 398-410.

Vangen, O., Holm, B., Valros, A., Lund, M.S. and Rydhmer, L., 2005. Genetic variation in sows' maternal behaviour, recorded under field conditions. Livestock Production Science 93: 63-71.

Von Borell, E., Baumgartner, J., Giersing, M., Jäggin, N., Prunier, A., Tuyttens, F.A.M. and Edwards, S.A., 2009. Animal welfare implications of surgical castration and its alternatives in pigs. Animal 3: 1488-1496.

Von Borell, E., Dobson, H. and Prunier, A., 2007. Stress, behaviour and reproductive performance in female cattle and pigs. Hormones and Behavior 52: 130-138.

Weary, D.M., Braithwaite, L.A. and Fraser, D., 1998a. Vocal response to pain in piglets. Applied Animal Behaviour Science 56: 161-172.

Weary, D.M. and Fraser, D., 1995. Signalling need: costly signals and animal welfare assessment. Applied Animal Behaviour Science 44: 159-169.

Weary, D.M., Phillips, P.A., Pajor, E.A., Fraser, D. and Thompson, B.K., 1998b. Crushing of piglets by sows: effects of litter features, pen features and sow behaviour. Applied Animal Behaviour Science 61: 103-111.

Weeks, C., 2008. A review of welfare in cattle, sheep and pig lairages, with emphasis on stocking rates, ventilation and noise. Animal Welfare 17: 275-284.

Wemelsfelder, F., 2007. How animals communicate quality of life: the qualitative assessment of behaviour. Animal Welfare 16: 25-31.

Wemelsfelder, F., Batchelor, C., Jarvis, S., Farish, M. and Calvert, S., 2003. The relationship between qualitative and quantitative assessments of pig behaviour. In: Zootecniche, F.I.Z.e. (ed.) Proceedings of the $37^{\text {th }}$ International Congress of the International Society for Applied Ethology, Brescia, Italy, p. 42.

Wemelsfelder, F., Hunter, A.E., Paul, E.S. and Lawrence, A.B., 2012. Assessing pig body language: agreement and consistency between pig farmers, veterinarians, and animal activists. Journal of Animal Science 90: 3652-3665.

Wemelsfelder, F., Hunter, E.A., Mendl, M.T. and Lawrence, A.B., 2000. The spontaneous qualitative assessment of behavioural expressions in pigs: first explorations of a novel methodology for integrative animal welfare measurement. Applied Animal Behaviour Science 67: 193-215.

White, R.G., Deshazer, J.A., Tressler, C.J., Borcher, G.M., Davey, S., Waninge, A., Parkhurst, A.M., Milanuk, M.J. and Clemens, E.T., 1995. Vocalization and physiological response of pigs during castration with or without a local anesthetic. Journal of Animal Science 73: 381-386. 